\title{
Mechanisms of Atlantic Meridional Overturning Circulation variability simulated by the NEMO model
}

\author{
V. N. Stepanov and K. Haines \\ Dept. of Meteorology, University of Reading, Reading, UK \\ Correspondence to: V. N. Stepanov (vlnst@hotmail.co.uk)
}

Received: 7 March 2013 - Published in Ocean Sci. Discuss.: 27 March 2013

Revised: 3 June 2014 - Accepted: 9 June 2014 - Published: 14 July 2014

\begin{abstract}
We have investigated mechanisms for the Atlantic Meridional Overturning Circulation (AMOC) variability at $26.5^{\circ} \mathrm{N}$ (other than the Ekman component) that can be related to external forcings, in particular wind variability. Resolution dependence is studied using identical experiments with $1^{\circ}$ and $1 / 4^{\circ}$ NEMO model runs over 1960-2010.

The analysis shows that much of the variability in the AMOC at $26^{\circ} \mathrm{N}$ can be related to the wind strength over the North Atlantic, through mechanisms lagged on different timescales. At $\sim 1$-year lag the January-June difference of mean sea level pressure between high and mid-latitudes in the North Atlantic explains 35-50\% of the interannual AMOC variability (with negative correlation between wind strength and AMOC). At longer lead timescales $\sim 4$ years, strong (weak) winds over the northern North Atlantic (specifically linked to the NAO index) are followed by higher (lower) AMOC transport, but this mechanism only works in the $1 / 4^{\circ}$ model. Analysis of the density correlations suggests an increase (decrease) in deep water formation in the North Atlantic subpolar gyre to be the cause. Therefore another $30 \%$ of the AMOC variability at $26^{\circ} \mathrm{N}$ can be related to density changes in the top $1000 \mathrm{~m}$ in the Labrador and Irminger seas occurring $\sim 4$ years earlier.
\end{abstract}

\section{Introduction}

Many model results (e.g. Delworth and Greatbatch, 2000; Eden and Willebrand, 2001; Dong and Sutton, 2005; Lohmann et al., 2009a, b; Lazier et al., 2002; Böning et al., 2006; Deshayes and Frankignoul, 2008) show that strong winds over the North Atlantic (characterized by the positive North Atlantic Oscillation (NAO) index) lead to an increase in the Atlantic Meridional Overturning Circulation (AMOC), through an increase in deep water formation in the North Atlantic subpolar gyre, e.g. Marshall et al. (2001) and Visbeck et al. (2003). Other model results suggest that reduction of buoyancy forced deep convection in the subpolar gyre can also lead to a decline in the AMOC (Häkkinen and Rhines, 2004; Bersch et al., 2007). The timescale of this mechanism depends on modelling both the water formation and western boundary wave propagation processes. We refer to this as the subpolar-forced variability.

Another mechanism for changing the AMOC is through Ekman pumping changes over the subtropical gyre. Changes in wind stress lead to wind stress curl change impacting both Ekman pumping and gyre transports (Eden and Willebrand, 2001; Marshall et al., 2001). These wind changes can lead to very rapid adjustments if they occur near the western and eastern boundaries where the resulting Ekman pumping can immediately impact cross-basin density gradients (Kanzow et al., 2010; Hermanson et al., 2014). We refer to this as subtropical forced variability.

The aim of this paper is to demonstrate that both windrelated mechanisms operate in the same model, are identified by different lags linked to model adjustment, and that AMOC responses depend on model resolution. Although we do not separate direct wind stress mechanisms from buoyancy forcing (i.e. the effect of heat and freshwater surface fluxes; see Robson et al., 2012), the two effects are correlated in reality and the correlations we detect are still clearly due to surface forcing changes. Ocean variability can of course also be caused by internal ocean variability (e.g. Simonnet et al., 2005; Hirschi et al., 2013) which also depends upon model resolution. Coupled ocean-atmosphere models of sufficient resolution would also generate internal AMOC variability 
although this would likely still be traceable through the wind variability mechanisms described here.

We will investigate the subpolar and subtropical windforced mechanisms of AMOC variability at $26.5^{\circ} \mathrm{N}$ using analyses of $1^{\circ}$ and $1 / 4^{\circ}$ NEMO model data. The finerresolution model incorporates ocean eddies that may be important for the interannual variability of both the ocean heat transport (Volkov et al., 2008), and the AMOC (Biastoch et al., 2008; Kanzow et al., 2010; Hirschi et al., 2013). There is evidence from different model studies that the wave adjustment processes are usually faster in higher-resolution models (Döscher et al., 1994; Getzlaff et al., 2005; Roussenov et al., 2008; Zhang, 2010; Hodson and Sutton, 2012), probably due to an improved simulation of boundary (Döscher et al., 1994) and coastally trapped, (Wang and Mooers, 1976) waves, which can impact the propagation of AMOC anomalies. The variability of AMOC transport in the top $\sim 1000 \mathrm{~m}$ at $26.5^{\circ} \mathrm{N}$ without the Ekman component has been analysed (henceforth referred to as AMOC-Ek). The "Ek" component was computed from the wind stress fields used to force the model, with a barotropic return flow assumed similar to Cunningham et al. (2007). Since all the direct Ekman transport is in the upper limb of the AMOC, the barotropic closure, which is applied in a zonally uniform way, allows Ek to be unambiguously calculated. Apart from Fig. 1, a linear trend (least squares) and seasonal cycle (whole period monthly average values) were removed from all model fields before further analysis. Section 2 briefly introduces the NEMO model and forcing methods and describes the numerical experiments and Sect. 3 presents the results of correlation analyses. Section 4 shows the model relationships between atmospheric and ocean characteristics. Section 5 provides discussion and conclusions on the link between wind forcing and the AMOC variability.

\section{Description of the model and numerical experiments}

The numerical model used is the NEMO coupled iceocean model (Madec, 2008) version 2.3, based on the OPA9 ocean model (Madec et al., 1998) and the LIM2.0 sea ice model (Louvain sea ice model: Fichefet and Maqueda, 1997; Goosse and Fichefet, 1999), which is a dynamicthermodynamic model specifically designed for climate studies. This model setup is well covered in the literature (e.g. see Barnier et al., 2006; Barnier and the DRAKKAR Group, 2007, and Penduff et al., 2007, 2010) because it is the NEMO modelling framework that is now being used throughout Europe both for scientific and operational work (e.g. see Huck et al., 2008; Chanut et al., 2008; Lorbacher et al., 2010; Gary et al., 2011). The ocean model is a primitive equation $z$ level model making use of the hydrostatic and Boussinesq approximations. The model employs a linear free surface (Roullet and Madec, 2000) with partial cell topography (Adcroft et al., 1997). The version used here has a tri-polar "ORCA" grid and

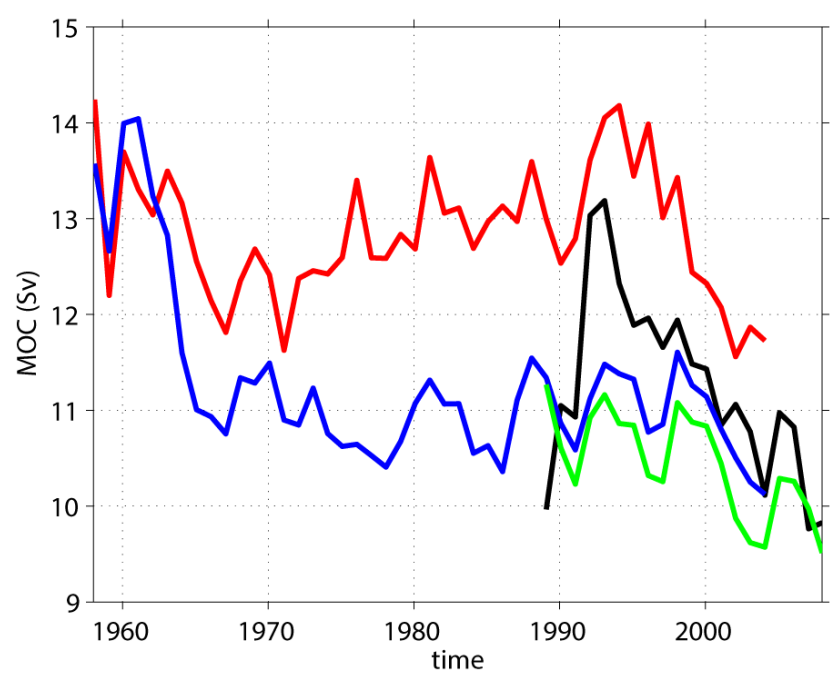

Figure 1. Time series of annual mean AMOC-Ek variability for the 4 model runs studied in this paper before they are linearly detrended and deseasoned. ORCA025-G70 (red), ORCA1-R07 (blue), ORCA025-ERA (black), and ORCA1-ERA (green).

46 levels in the vertical, with thicknesses ranging from $6 \mathrm{~m}$ at the surface to $250 \mathrm{~m}$ at the ocean bottom. The model configuration has a global $1^{\circ}$ resolution with a tropical refinement to $1 / 3^{\circ}$ (ORCA1) and a global $1 / 4^{\circ}$ resolution (ORCA025) with horizontal resolution $27.75 \mathrm{~km}$ at the equator, $13.8 \mathrm{~km}$ at $60^{\circ} \mathrm{N}$, and to $10 \mathrm{~km}$ in the Arctic Ocean. The configuration has been developed through the DRAKKAR Consortium (Barnier and the DRAKKAR Group, 2007) and uses model parameter settings as defined in Barnier et al. (2006) and Penduff et al. (2010). The configuration employs an energyenstrophy conserving momentum advection scheme (Barnier et al., 2006) and a Laplacian diffusion. Horizontal viscosity is parameterized with a Laplacian operator. Additionally, the ORCA1 configuration makes use of the Gent and McWilliams (1990) mixing parameterization. Vertical mixing is parameterized using a one-equation turbulent kinetic energy scheme (Blanke and Delecluse, 1993). To prevent drift in global salinity due to deficiencies in the fresh water forcing, a sea surface salinity relaxation to climatology is applied, with a timescale of 180 days for the top $6 \mathrm{~m}$ at the icefree surface, decreasing to 60 days under ice for ORCA025 and correspondingly 36 and about 7 days for ORCA1. More details may be found in Barnier et al. (2006), and Penduff et al. (2007).

The NEMO model was forced by two atmospheric data sets. The two long (1958-2004) runs (one at each resolution, ORCA025-G70 at $1 / 4^{\circ}$ and ORCA1-R07 at $1^{\circ}$ ) were forced by the hybrid DFS3 (DRAKKAR Forcing Set 3) atmospheric fields, with bulk fluxes calculated as in Large and Yeager (2004). Both runs were initialized from the World Ocean Atlas 2005 (WOA05) $1^{\circ}$ resolution gridded climatology (Boyer et al., 2006). The DFS3 fields have been 
thoroughly evaluated with the NEMO model at various resolutions and have been shown to provide balanced and physically consistent results (Brodeau et al., 2009). In DFS3 the long- and short-wave radiative fluxes are derived from the CORE data set (daily means), while the surface winds, temperature and humidity are taken from the ERA-40 ECMWF reanalysis for 1958-2001, and from ECMWF operational analyses thereafter.

The second set of surface atmospheric forcing for the shorter period 1989-2008 is obtained from ECMWF ERAInterim reanalysis (Simmons et al., 2007; Dee and Uppala, 2009). The ERA-Interim reanalysis provides $10 \mathrm{~m}$ wind, $2 \mathrm{~m}$ air humidity and $2 \mathrm{~m}$ air temperature, which are used to compute 6-hourly turbulent air/sea and air/sea-ice fluxes during model integration using the bulk formula proposed by Large and Yeager (2004). Downwelling short- and longwave radiative fluxes and precipitation are also provided by ERA-Interim. For all model runs monthly runoffs (Dai and Trenberth, 2002) are applied along the land mask. More details about the model configuration and the simulation results may be found in Barnier et al. (2006), Penduff et al. (2007, 2010), Smith and Haines (2009), Smith et al. (2010), Stepanov et al. (2012) and Haines et al. (2012).

The short 1989-2008 period is also simulated in the $1^{\circ}$ (ORCA1-ERA) and the 1/4 (ORCA025-ERA) models, with experiments summarized in Table 1. For the ORCA1-ERA experiment the initial conditions are from the World Ocean Atlas 2005 (WOA05) climatology (Boyer et al., 2006) with a cold start in January 1989, i.e. no initial circulation, and then forced with ERA-Interim. The equivalent ORCA025ERA experiment has been described elsewhere (Haines et al., 2012) as the free control run associated with the reanalysis UR025.3, initiated from a previous $1 / 4^{\circ}$ run driven with hydrographic data assimilation (Smith and Haines, 2009), but run over 1989-2010 forced by ERA-Interim forcing. Since the ERA-Interim and DFS3 forcings will be quite similar where the periods overlap, these shorter period runs effectively test the sensitivity of the AMOC response to initial conditions.

\section{Correlations of AMOC and density in the NEMO model}

We now examine the differences between the model runs in their responses to the imposed forcing. Figure 1 shows the annual time series of AMOC-Ek from the four model runs described in the paper before they are linearly detrended and deseasoned. All runs show relatively similar short-period variability. The long high-resolution run ORCA025-G70 also shows low-frequency variability, with a slow rise in AMOC from 1970 to 1995, with a decline thereafter. The equivalent low-resolution run ORCA1-R07 does not show this lowfrequency variability, and ORCA1-ERA similarly shows no peak in 1995. The shorter ORCA025-ERA run does show higher AMOC variations in the early 1990s but the response is more unsteady. We will see later that there is at least a 4year lag in AMOC response to forcing in the subpolar gyre and so the differences between the high-resolution runs are due mainly to differences in the initial conditions in 1989, although there will also be some differences due to internally generated variability, e.g. Hirschi et al. (2013). For the long G70 run the low-frequency AMOC variance dominates and so we expect fields correlated with the AMOC to mainly pick out the processes associated with this low-frequency variance.

The importance of both deep and shallow density distributions in driving the AMOC in the different models is now examined. Figure 2a, c show the annual mean correlations between AMOC-Ek at $26.5^{\circ} \mathrm{N}$ and the $1000-3000 \mathrm{~m}$ averaged density anomalies in the ORCA1-R07 and ORCA025G70 models, for 1960-2004 inclusive. The high densities along the western boundary and lower densities on the eastern boundary at $26.5^{\circ} \mathrm{N}$ indicate stronger vertical shear and hence stronger AMOC. While the eastern spatial patterns are qualitatively similar between the two models, the western correlation patterns are quite different.

Deep layer density correlations from ORCA1-R07 are confined to the subtropical gyre reaching only $\sim 40-45^{\circ} \mathrm{N}$ on the western boundary, and extending well into the basin interior. Figure 2i, $\mathrm{j}$ show correlations of Ekman pumping with the annual AMOC-Ek at $26.5^{\circ} \mathrm{N}$ in ORCA1-R07 (Fig. 2i) and ORCA025-G70 (Fig. 2j), for the 45-year period 19602004 inclusive, with periods longer than 12 months removed with a Cosine (Hann) filter. The correlation patterns between AMOC-Ek and Ekman pumping near the western boundary of the subtropical gyre in ORCA1-R07 (Fig. 2i) are very similar to patterns presented in Fig. 2a, while the same correlations in ORCA025-G70 are quite different (i.e. Fig. $2 \mathrm{c}$ and j). The deep layer density correlations from ORCA1-R07 are consistent with the subtropical forcing mechanism, when wind stress curl changes impact the strength of the zonal density gradient and hence the AMOC.

In ORCA025-G70 the same density correlations are confined to a narrow strip at the western boundary of the subtropical gyre, which extends up into the subpolar gyre where the influence spreads and fills the Labrador and Irminger seas. These correlations are consistent with dense water formation in the high latitudes influencing density down the western boundary (e.g. see Hodson and Sutton, 2012). In particular, this associates the low-frequency signals seen in Fig. 1 with a Labrador Sea origin. There are weaker correlations with upper Labrador sea densities above $1000 \mathrm{~m}$ also, which extend partway down the western boundary and then terminate (Fig. 2b, d). This probably reflects the extent of advected denser water anomalies at these upper levels which terminate at the intergyre boundary. The ORCA1-R07 shows some correlation between AMOC-Ek and dense water in the Labrador Sea, but the area of correlations is much smaller, it is not clearly connected with the western boundary, and 

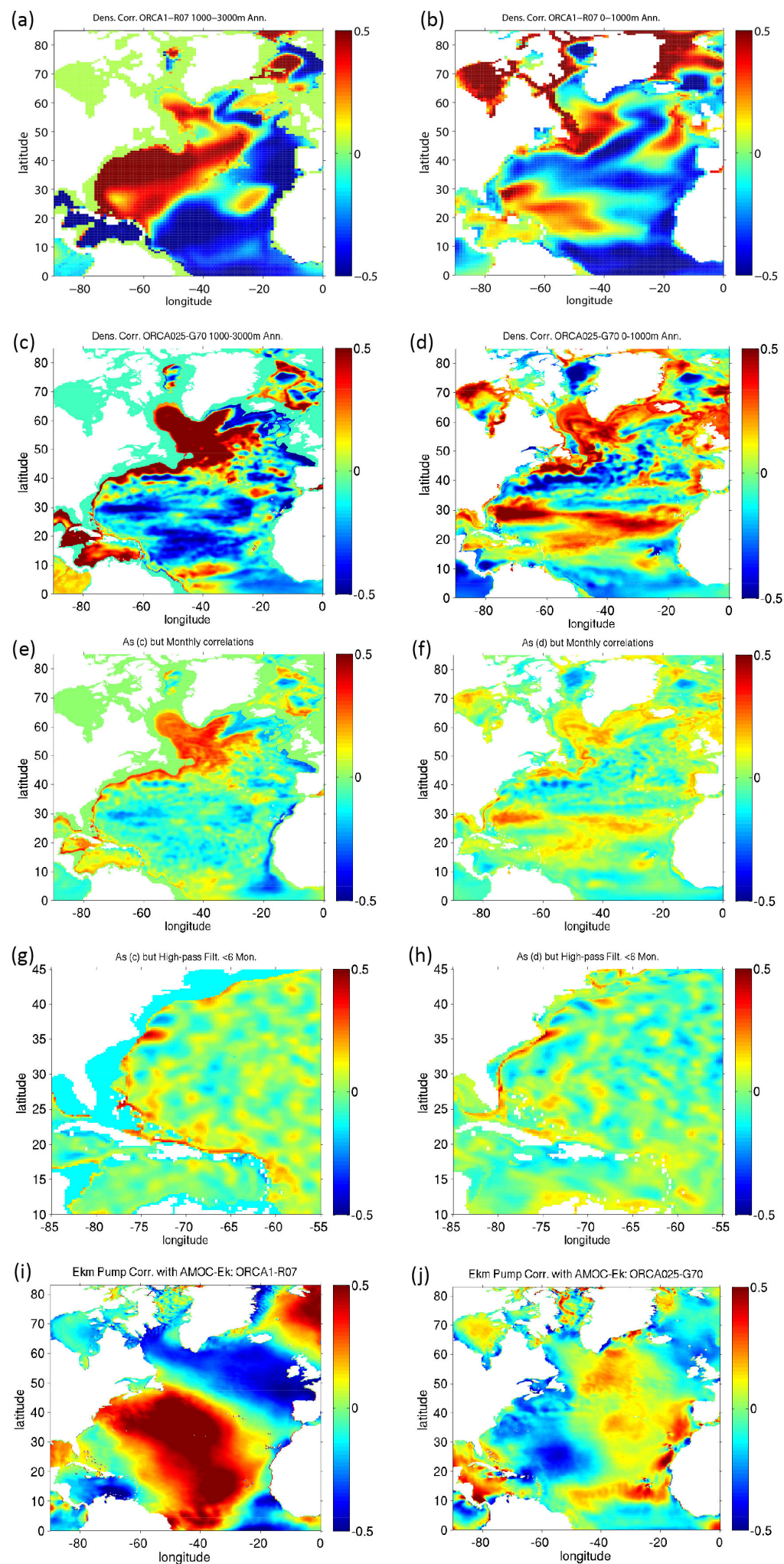

Figure 2. Correlations of the annual AMOC-Ek at $26.5^{\circ} \mathrm{N}$ with the $1000-3000 \mathrm{~m} \mathrm{(a,c)} \mathrm{and} \mathrm{the} \mathrm{top} 1000 \mathrm{~m}$ (b, d) averaged density anomalies in ORCA1-R07 (a, b) and ORCA025-G70 (c, d) runs, for the 45-year period 1960-2004 inclusive. (e, f) and (g, h): the same as (c, d) but calculated from monthly data and data after high-pass filtering with periods shorter than 6 months, respectively; (g, h) are shown in enlarged scale and the colour bar scales are the same as in (e, f). Annual correlations of Ekman pumping with the AMOC-Ek at $26.5^{\circ} \mathrm{N}$ in ORCA1R07 (i) and ORCA025-G70 (j), for the 45-year period 1960-2004 inclusive. Multi-annual timescales are removed by filtering out periods longer than 12 months. 
Table 1. Definition of the experiments used in this paper.

\begin{tabular}{cll}
\hline No. & Experiment & Description \\
\hline 1 & ORCA1-ERA & $\begin{array}{l}\text { Control } 1^{\circ} \text { NEMO simulation forced with ERA-Interim } \\
\text { and initialized from 1989 from WOA05 climatology }\end{array}$ \\
\hline 2 & ORCA025-ERA & $\begin{array}{l}\text { Control 1/4 } 4^{\circ} \text { NEMO forced with ERA-Interim; the initial } \\
\text { ocean and sea ice states are taken from previous ocean } \\
\text { reanalysis; see Haines et al. (2012) }\end{array}$ \\
\hline 3 & ORCA1-R07 & $\begin{array}{l}\text { Control } 1^{\circ} \text { NEMO simulation forced with the hybrid } \\
\text { interannual forcing DFS3 during 1958-2004 }\end{array}$ \\
\hline 4 & ORCA025-G70 & $\begin{array}{l}\text { Control 1/4 } \\
\text { interannual forcing DFS3 during 1958-2004 }\end{array}$ \\
\hline
\end{tabular}

these correlations disappear if only 20 years of data (19892008) are used, whereas the Labrador Sea correlations in the higher-resolution model are still robust for 20 years of data.

The fact that AMOC-Ek at $26.5^{\circ} \mathrm{N}$ is not robustly correlated to deep Labrador Sea densities in the $1^{\circ}$ model suggests that the coarse model may not adequately resolve the boundary wave propagation mechanism (this agrees with Hodson and Sutton (2012) who show that the timescale of deep ocean evolution of the western boundary anomaly is sensitive to resolution). Figure 2e, f show ORCA025-G70 correlations now using monthly data. Most of the signals are similar to the annual-only correlations in Fig. 2c, d but with reduced correlations presumably due to more noise at the sub-annual frequency. However, in the top $1000 \mathrm{~m}$ there are interesting differences at the western boundary. With monthly timescales included there is a correlated signal stretching from $40^{\circ} \mathrm{N}$ to $26^{\circ} \mathrm{N}$ very close to the western boundary, while this signal is absent in the annual correlations. This signal is still present with high pass filtering to timescales of 6 months or less, Fig. $2 \mathrm{~g}$, h, and so we take this to be the signal of fast boundary waves similar to the HadCM3 results in Hermanson et al. (2014).

The difference between the $1^{\circ}$ and $1 / 4^{\circ}$ model correlation patterns in the subtropical gyre is likely due to higher mesoscale density variability in the $1 / 4^{\circ}$ model compared to $1^{\circ}$. Figure 3 shows the standard deviation of monthly density variability in the two models, at $1000-3000 \mathrm{~m}$ and in the top $1000 \mathrm{~m}$. Areas of higher density variability at higher resolution will mask correlations from Ekman-pumped density anomalies throughout the subtropical gyre. We can see an area with high correlations in the subtropics to the south of $30^{\circ} \mathrm{N}$ (Fig. $2 \mathrm{~b}, \mathrm{~d}$ ), where the density variability is lower (Fig. 3c, d), in both ORCA1-R07 and ORCA025-G70 runs. To the north of $30^{\circ} \mathrm{N}$ the correlation coefficients are smaller (Fig. 2b, d) because mesoscale variability is high here (Fig. 3c, d). We can see the same patterns of model correlations (Fig. 2a, c) and density variability for the $1000-3000 \mathrm{~m}$ layer (Fig. 3a, c).
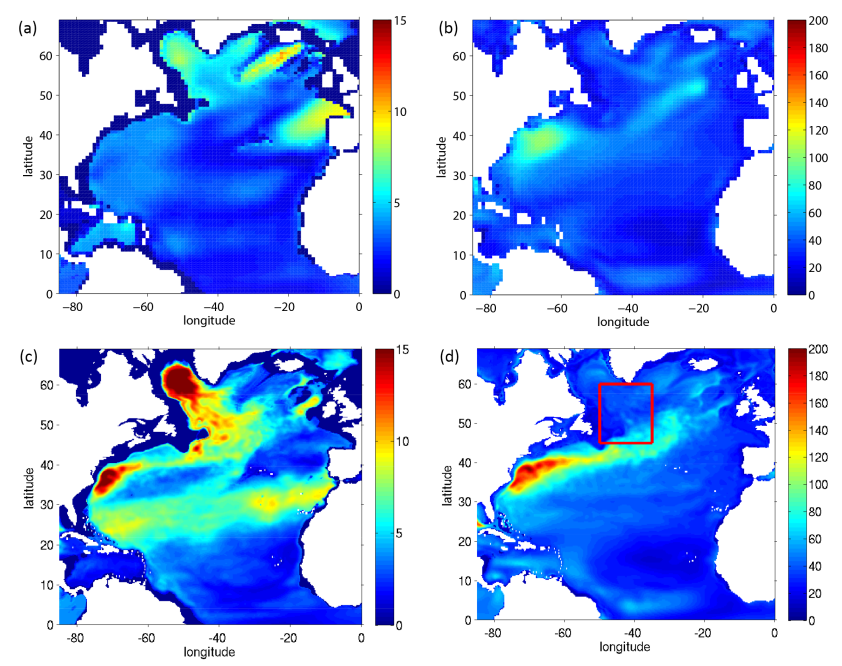

Figure 3. The standard deviations of the monthly density (in $\mathrm{g} \mathrm{m}^{-3}$ ) averaged on the 1000-3000 $\mathrm{m}(\mathbf{a}, \mathbf{c})$ and the top $1000 \mathrm{~m}(\mathbf{b}, \mathbf{d})$ layers in ORCA1-R07 (a, b) and ORCA025-G70 (c, d) runs (for the 45year period 1960-2004 inclusive). Also shown in the right bottom panel by red rectangle is the region that is used to calculate density anomaly (area between $50-35^{\circ} \mathrm{W}$ and $45-60^{\circ} \mathrm{N}$ ).

There is also a substantial difference in dense water formation in the Labrador and Irminger seas reproduced by the $1^{\circ}$ and $1 / 4^{\circ}$ NEMO models. Figure 4 presents, for ORCA025G70, the annual time series of AMOC-Ek transport anomaly at $26.5^{\circ} \mathrm{N}$ (thick red dashed line) and density anomaly averaged over the Labrador and Irminger seas (thick blue dashed line) between $50-35^{\circ} \mathrm{W}$ and $45-60^{\circ} \mathrm{N}$ (red rectangle marked in Fig. 3d) in the 1000-3000 m layer (Fig. 4a), and AMOCEk lagged by 4 years against density in the top $1000 \mathrm{~m}$ (Fig. 4b). The deep layer shows the highest correspondence at zero lag (correlation 0.75), while in the top $1000 \mathrm{~m}$ the AMOC lags by 4 years (correlation 0.64). All correlations presented are statistically significant with a probability of $95 \%$, which was determined through the effective number of degrees of freedom following Bretherton et al., 1999). We 
conclude that in the ORCA025-G70 model about 4 years is needed for the upper ocean signal to reach deeper layers in the Labrador and Irminger seas, and then this deeper density variability rapidly influences AMOC transports at $26.5^{\circ} \mathrm{N}$ with zero lag, Fig. 4a.

The thin solid lines (red and blue) in Fig. 4a, b show the same quantities from the ORCA1-R07 model. The Labrador Sea variability is very similar in the top $1000 \mathrm{~m}$, especially during the larger changes around 1995, presumably reflecting the same surface forcing. However, in the deeper layers the amplitude of density anomalies is considerably reduced, despite the same surface forcing, hence the stratification in the Labrador and Irminger seas for the $1^{\circ}$ and $1 / 4^{\circ}$ NEMO models is different, resulting in different processes of deep water formation in the two models and subsequently leading to different AMOC driving. We suggest that the different circulations in the subpolar gyre at $1^{\circ}$ allow dense water to be more easily exported from the Labrador and Irminger seas at upper levels, thereby reducing the amount of the deepest dense waters formed. A mechanism that could enable this export in denser waters is the operation of the Gent and McWilliams (1990) eddy parameterization scheme in ORCA1-R07 but not in ORCA025-G70. This would then explain why the AMOC-Ek transport anomalies in ORCA1R07 show reduced correlations with the subpolar gyre.

\section{Mechanisms and timescales of ocean response to forcing}

\subsection{Wind strength and the AMOC}

If the long-term AMOC variability due to deep water density in the Labrador and Irminger seas is discounted then the AMOC variability in both the $1^{\circ}$ and $1 / 4^{\circ}$ models in Fig. 1 is fairly similar reflecting direct wind driving in the subtropical gyre. In ORCA025-G70 the amplitude of interannual AMOC variability decreases from 0.65 to $0.45 \mathrm{~Sv}$ after the very long timescales, > 13 year Hanning filter, are removed, and is very comparable to the ORCA1-R07 variability $(0.4 \mathrm{~Sv})$. However the high-frequency ORCA1-R07 variability at timescales $<3$ months is $50 \%$ less than in ORCA025-G70 showing that both the lowest and highest frequency AMOC variability are inadequately reproduced by the $1^{\circ}$ model.

Since the vertical resolution and external forcings in the $1^{\circ}$ and $1 / 4^{\circ}$ models are identical, the AMOC differences in these long runs should be due to differences in the ocean models. At higher resolution the greater internal variability might lead to a significant difference in high frequency AMOC variability, while the Gent and McWilliams (1990) eddy parameterization scheme may also significantly impact the deep water formation in the subpolar gyre, thus influencing low-frequency AMOC variability.

The higher resolution results in more intense gyre circulation, particularly near the western boundary and in the
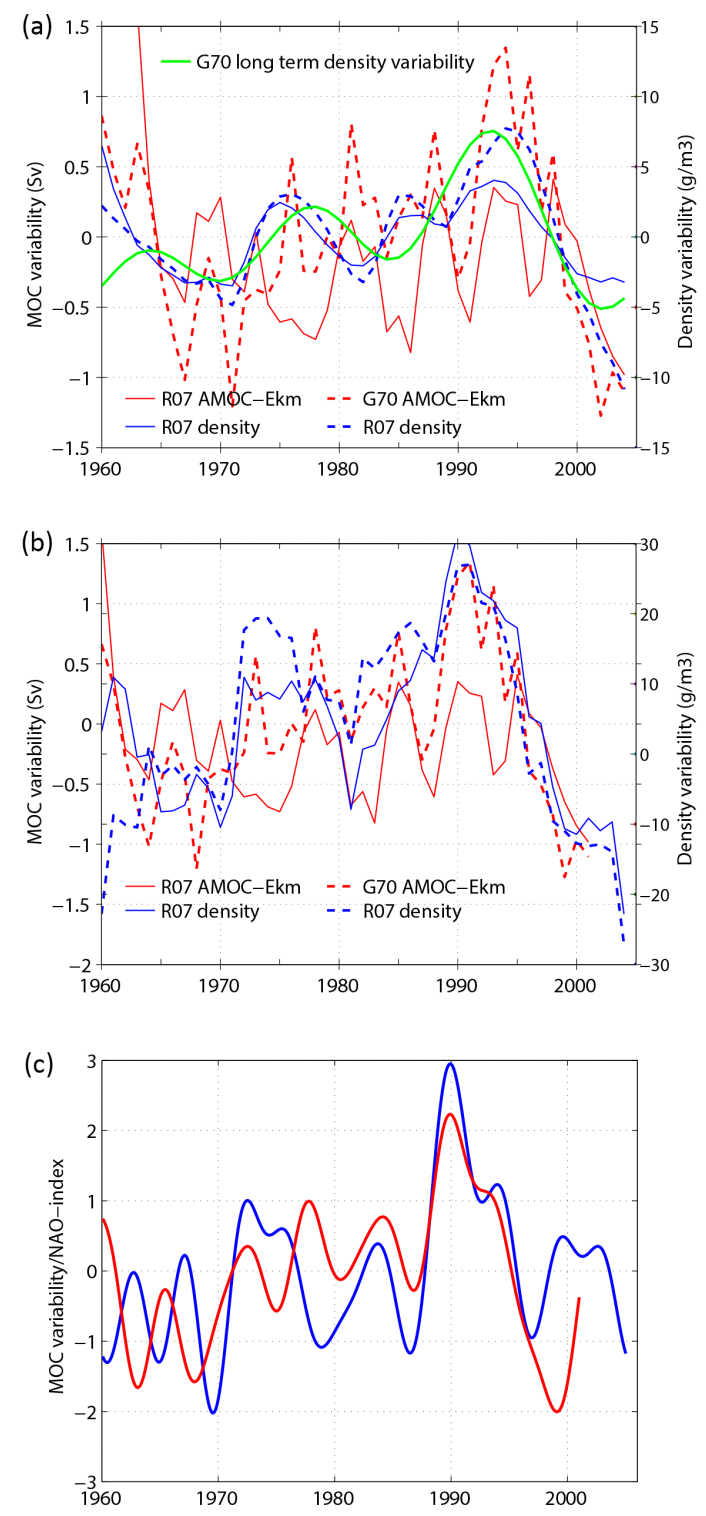

Figure 4. Annual time series of AMOC-Ek transport anomaly at $26.5^{\circ} \mathrm{N}$ (red) and density anomaly (blue) averaged over the Labrador and Irminger seas (between $50-35^{\circ} \mathrm{W}$ and $45-60^{\circ} \mathrm{N}$ ) in 1000-3000 m layer (a) and in the top $1000 \mathrm{~m}$ (b). Thin solid and thick dashed lines correspond to ORCA1-R07 and ORCA025-G70 runs, respectively. Long-term (after use of low-pass filter with periods longer than 13 years) ORCA025-G70 density variability in $1000-3000 \mathrm{~m}$ layer is shown by green solid thick line in Fig. 4a. The AMOC plots in Fig. 4b lag at 48 months compared to density curves; (c) - NAO index (blue) and AMOC-Ek variability at $26.5^{\circ} \mathrm{N}$ (red) after low-pass filtering with periods longer than 48 months and normalized to unit variance to have zero mean and a standard deviation of one; here AMOC time series is shifted 48 months back relative to the NAO index. To make panels (a) and (b) more readable, shorter names R07 and G70 for legend have been used for the experiments ORCA1-R07 and ORCA025-G70 respectively. 

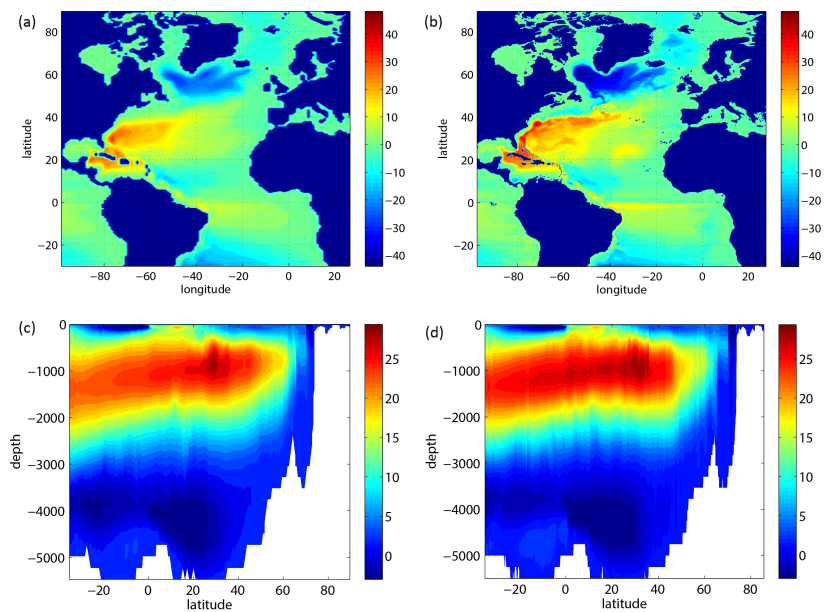

Figure 5. 45-year averaged barotropic and AMOC stream functions (in Sv) for ORCA1-R07 (a, c) and ORCA025-G70 (b, d), respectively.

Labrador Sea. Figure 5a, b, show the barotropic stream functions, where the subpolar gyre circulation in ORCA025-G70 penetrates farther to the south along the western boundary via the subpolar cyclonic circulation, compared to ORCA1R07. This stronger subpolar gyre circulation is also associated with a much more extensive maximum in AMOC overturning in Fig. 5c, d.

The detrended and deseasoned monthly ORCA1-R07 and ORCA025-G70 AMOC-Ek time series are not obviously correlated with the NAO index (the correlation coefficients are not statistically significant), although the variability is still likely to show dependence upon wind forcing. However Fig. 6 shows correlation maps of the January-June average mean-sea-level pressures with the annual mean AMOCEk transport anomalies from ORCA1-ERA (Fig. 6a) and ORCA025-ERA (Fig. 6b), for 1989-2008 (similar patterns are obtained with the longer ORCA1-R07 and ORCA025G70 time series over the last 20 years, not shown). Higher values of AMOC transport correspond to higher sea level pressures over most of the subpolar gyre and particularly the Labrador Sea, and lower pressure over the subtropical gyre, i.e. weaker westerly winds are associated with higher AMOC transports. Figure $6 \mathrm{c}$ shows the AMOC-Ek transports from all model runs from 1989 onwards, along with the January-June mean pressure difference between high and mid-latitudes, $\triangle \mathrm{Pa}$ (at the points marked by black crosses in Fig. 6b). The annual AMOC transports are correlated with $\triangle \mathrm{Pa}$ with coefficients ORCA1-R07 (0.7), ORCA1ERA (0.7), ORCA025-G70 (0.7) and ORCA025-ERA (0.6), all coefficients being statistically significant at $95 \%$. The January-June mean NAO index (with reversed sign, referred to as $\mathrm{NAO}^{-}$) is shown as a red dashed line in Fig. 6c. The $\triangle \mathrm{Pa}$ and $\mathrm{NAO}^{-}$variability are correlated at 0.6 . Similar annual correlations between $\mathrm{AMOC}-\mathrm{Ek}$ and $\mathrm{NAO}^{-}$are not statistically significant $(\sim 0.4$ for ORCA025-G70 and ORCA025-ERA, and -0.1 and -0.2 for ORCA1-R07 and ORCA1-ERA respectively).

A possible explanation for these correlations between AMOC-Ek and the winds could be due to Ekman pumping near the eastern or western boundaries, as in Hermanson et al. (2014) or Kanzow et al. (2010), but the analysis of the ORCA025-G70 model output below presents additional mechanisms that may be involved in these variations.

\subsection{The Gulf Stream north wall index, the NAO index and the AMOC}

Figure $6 \mathrm{~d}$ shows the observed January-June mean NAO index (solid line) and the annual Gulf Stream north wall index (henceforth as GSNW index) from http://www. pml-gulfstream.org.uk (dashed line), after the multi-annual timescales are removed. The GSNW index (see e.g. Taylor and Stephens, 1998) characterizes the latitude of the Gulf Stream front and therefore describes the north-south shifts of the Gulf Stream. The January-June mean NAO index is also correlated with the GSNW index with a significant coefficient of about 0.32 (unfiltered data are correlated with a coefficient of 0.5). A low NAO index corresponds to a southerly position of the Gulf Stream, which means greater southward penetration of the cold Labrador Sea water at the western boundary of the subpolar gyre $\sim 40^{\circ} \mathrm{N}$. We hypothesize that in our model this southward pulse from the subpolar gyre can excite baroclinic boundary waves that propagate south along the western boundary resulting in cooling and a higher AMOC (as indicated from the boundary correlations Fig. 2f, $\mathrm{h}$. The boundary correlations in Fig. $2 \mathrm{~h}$ for example first appear around cape Hatteras with a 3-month lead time (not shown), supporting this view.

Using the long ORCA025-G70 results, the leading EOF1 mode of monthly temperature anomalies at the western boundary of the North Atlantic is presented in Fig. 6e, and the time series of its normalized principal component PC1 is shown by the red line in Fig. 6d (note that multi-annual timescales (i.e. longer than 12 months) have been filtered out to focus on interannual and shorter timescales only). A crosscorrelation analysis between $\mathrm{PC} 1$ and the GSNW index at zero lag for 1966-2004 gives a correlation of 0.34 (statistically significant). The EOF1 pattern in Fig. 6e shows a cell of warm (cold) water near $35^{\circ} \mathrm{N}$ in the top $\sim 800 \mathrm{~m}$ when the Gulf Stream shifts to the north (south). The position of this cell is coincident with the maximum temperature variability at the western boundary (Fig. 6f), explaining about $21 \%$ of the total temperature variance. The filtering to remove periods longer than 12 months considerably increases the correlations between PC1 and the GSNW index (from 0.09 to 0.34). Taking into account the results presented in Fig. 6a$\mathrm{c}$ and the significance of correlations between AMOC-Ek at $26.5^{\circ} \mathrm{N}$ and the density anomalies at the western boundary also at short timescales (Fig. $2 \mathrm{~g}, \mathrm{~h}$ ), we can conclude that 

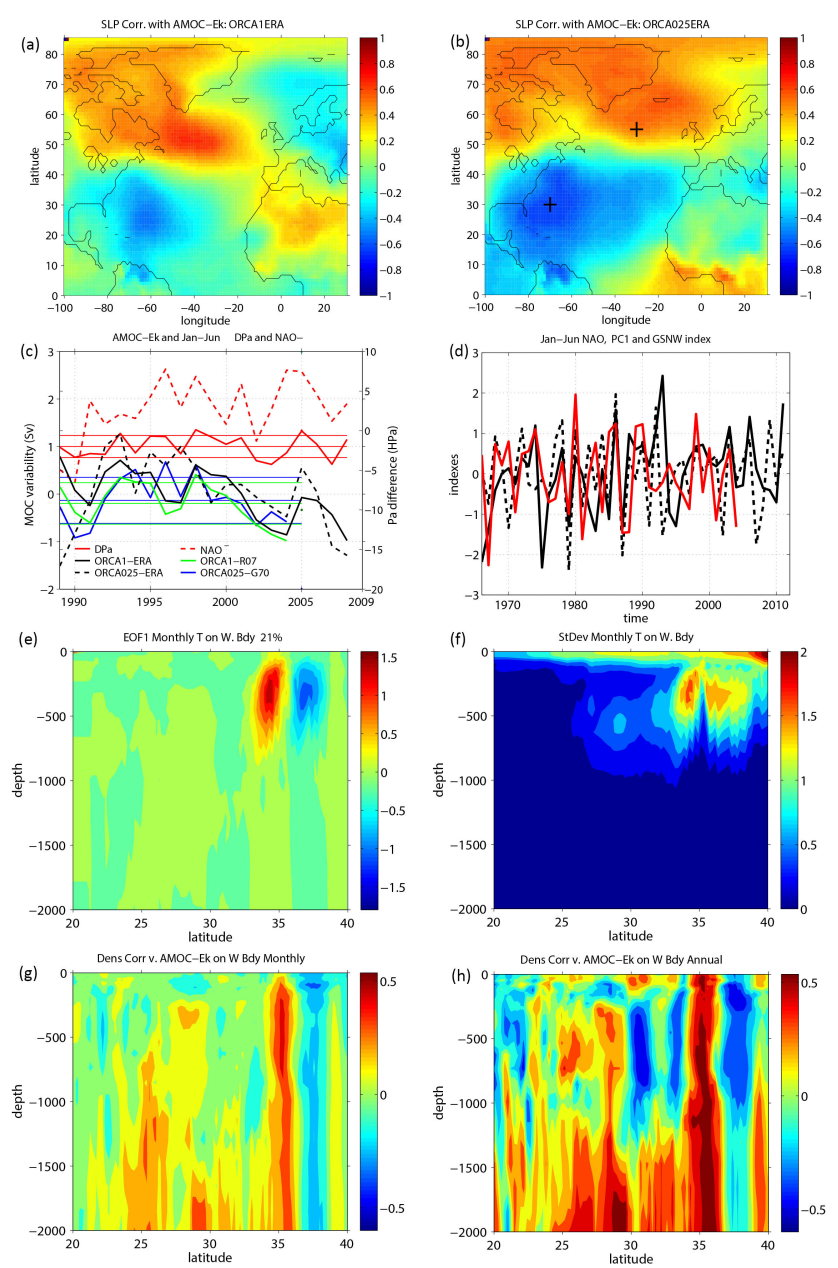

Figure 6. Correlation of sea level pressure with ORCA1-ERA (a) and ORCA025-ERA (b) AMOC-Ek transport for 1989-2008; (c) annual ORCA1-ERA (black), ORCA025-ERA (dashed black), ORCA1-R07 (green) and ORCA025-G70 (blue) AMOC-Ek transports at $26.5^{\circ} \mathrm{N}$ (in $\mathrm{Sv}$ ), and January-June mean $\triangle \mathrm{Pa}$ (red, in $\mathrm{hPa}$; see text) and January-June mean $\mathrm{NAO}^{-}$index (dashed red). Horizontal lines show mean values plus and minus standard deviations (for curves corresponding to the same colours); (d) January-June mean NAO index (black solid), PC1 (red; see text) and annual Gulf Stream north wall index (black dashed); (e) the first leading EOF mode (EOF1) of monthly temperature anomalies at the western boundary; (f) standard deviation of monthly temperature at the western boundary; $(\mathbf{g}, \mathbf{h})$ correlations of the AMOC-Ek at $26.5^{\circ} \mathrm{N}$ with density at the western boundary in ORCA025-G70 for the 45-year period 1960-2004 inclusive from monthly (g) and annual mean (h) data. For panels (d-h), variability on periods longer than 12 months have been filtered out.

the link between the north-south shifts of the Gulf Stream and density changes at the western boundary (mainly due to temperature variability) is likely due to boundary waves triggered by a shift of the Gulf Stream, with responses seen within 1 year. Therefore we see significant correlations between AMOC-Ek at $26.5^{\circ} \mathrm{N}$ and the top $1000 \mathrm{~m}$ averaged density anomalies at the western boundary in ORCA025$\mathrm{G} 70$ as a result of these high-frequency signals. Figure $6 \mathrm{~g}$, h show the vertical structure in western boundary density correlations with the AMOC-Ek at $26.5^{\circ} \mathrm{N}$ in ORCA025-G70, - using monthly (Fig. 6g), and only annual-mean (Fig. 6h) data. The density signal at $35^{\circ} \mathrm{N}$ extends from the surface to the deep layers and then southwards at depth to influence the AMOC at $26.5^{\circ} \mathrm{N}$ (e.g. as in Stepanov et al., 2012). Mostly the monthly correlations are similar to the annual-mean correlations but smaller, due to introducing noise at the subannual frequency.

\subsection{The link between the NAO, density variability and the AMOC}

After applying low-pass filtering for periods longer than 48 months to the NAO index and the ORCA025-G70 AMOC-Ek time series we get a positive correlation, with the NAO leading the AMOC-Ek by 48 months (Fig. 4c). This lag is in agreement with Fig. 4b showing the same lag between AMOC transport and density variability in the top $1000 \mathrm{~m}$, and is also consistent with Robson et al. (2012) as well as other observations. For example, after the NAO index reached its peak values in the early 1990s a layer of anomalously cold Labrador Sea water was formed (Yashayaev et al., 2007) due to increased deep convection in the Labrador Sea, particularly in the years 1990-1993 (Lazier et al., 2002).

We conclude that in the ORCA025-G70 run about $30 \%$ of the total interannual variability in AMOC-Ek transport is due to dense water formation in the Labrador and Irminger seas (the standard deviation of interannual ORCA025-G70 AMOC variability after removing the low-frequency component decreases from 0.65 to $0.45 \mathrm{~Sv}$ ), and this variability in turn depends on the wind strength over the subpolar gyre 4 years earlier acting to deepen Labrador Sea convection. Another $35-50 \%$ of the AMOC variability (based on the correlation coefficients between $\triangle \mathrm{Pa}$ and AMOC-Ek obtained from all model runs) is described by the January-June sea level pressure differences between high and mid-latitudes over the North Atlantic (which are correlated with the NAO index at 0.6). The AMOC fluctuations in ORCA025-G70 have more high-frequency variability compared to ORCA1R07 due to the better resolution of fast mesoscale processes: either processes occurring in the subtropical gyre near the western boundary, or better transmission across latitudes via western boundary waves.

Figure 7 shows 4-year lagged correlations of the annual AMOC-Ek at $26.5^{\circ} \mathrm{N}$ with the top $1000 \mathrm{~m}$ averaged, density anomalies (Fig. 7a) and sea level (Fig. 7b) in the ORCA025G70 model, for the 45-year period 1960-2004. For ease of comparison the correlations between AMOC-Ek and sea level are multiplied by -1 . The correlation patterns are very similar, suggesting that sea level variability can be used as a proxy for the top $1000 \mathrm{~m}$ averaged density variability near the western boundary, and particularly in the Labrador Sea 

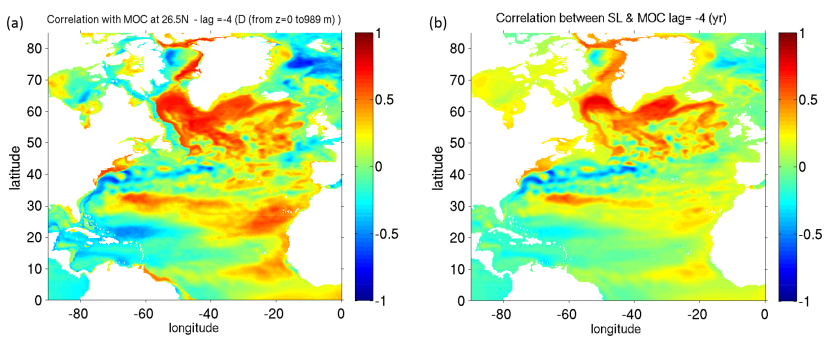

Figure 7. Correlations of the annual AMOC-Ek at $26.5^{\circ} \mathrm{N}$ with the top $1000 \mathrm{~m}$ averaged density anomalies (a) and sea level (b) in ORCA025-G70, for the 45-year period 1960-2004 inclusive; AMOC-Ek variability lags by 4 years. The correlations between AMOC-Ek and sea level are multiplied by -1 .

where it is most highly correlated with AMOC variability (Fig. 2d, f). Comparing Figs. 7a and 2d we can see the clear strengthening of higher-latitude correlations when introducing the 4-year lag.

The above correlations are consistent with rapid warming of the subpolar gyre in the mid-1990s which followed a prolonged positive phase of the NAO, with a sudden switch to a strongly negative NAO index in 1995-1997. Robson et al. (2012) suggest that both these factors led to high northward meridional heat transports causing the warming.

\subsection{Total AMO variability due to the NAO driven AMOC}

Numerical experiments with the $1^{\circ}$ model show that if the AMOC transport increases at some subtropical latitude (e.g. at $26.5^{\circ} \mathrm{N}$ by means of the assimilation of data near the western boundary from the RAPID array, Stepanov et al., 2012), this leads to a heat transport increase during the next 2 years, warming the area of subtropical gyre to the north, particularly along the Gulf Stream path. Large changes in ocean heat content then develop at higher latitudes, in particular around the water formation areas of the Labrador and Irminger seas. This warming results in an increase in stratification in the top $800 \mathrm{~m}$ layer at $\mathrm{mid} / \mathrm{high}$ latitudes making it less susceptible to wintertime convection. As a result the AMOC transport decreases after 2 years due to this negative feedback on water distributions at higher latitudes. Thus, the decline in the AMOC can be driven by a preceding increase in the northward heat transport (correlated with the AMOC transport), and according to this model, the lag between temperature changes in the northern (southern) part of subtropical (polar) gyre and AMOC changes is of about 2 years. In Fig. 8 the Atlantic Multidecadal Oscillation (www.esrl.noaa. gov/psd/data/correlation/amon.us.data, AMO) is shown as a dashed line. The AMO characterizes the changes in average sea surface temperature (SST) in the Northern Atlantic. One can see that when SST in the North Atlantic reaches some local maximum, it typically then drops over the following

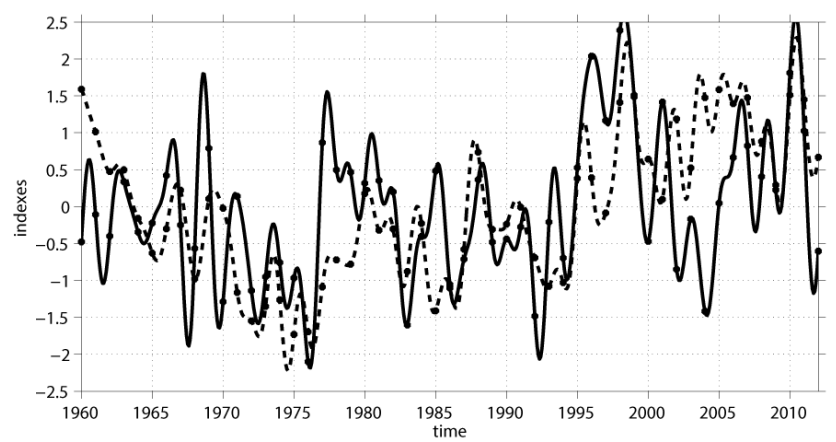

Figure 8. Normalized NAO(AMOC) (solid line; see text) and AMO index (dashed) after low-pass filtering with periods longer than 18 months, stars show January for each year.

2 years, which could be consistent with the mechanism involving AMOC changes described above.

So if there is a lag of 2 years between temperature changes in the North Atlantic and the AMOC change at $26.5^{\circ} \mathrm{N}$, and a lag of 4 years between the long-term variability of the AMOC and the NAO index (Fig. 4c), then we might expect a correlation between the NAO and AMO indices (see Fig. 6c) after a lag $\sim 6$ years. Figure 8 shows the result of a multiple regression analysis (henceforth $\mathrm{AMO}(\mathrm{NAO})$ ) that allows to build a regression equation of the form

$$
\begin{aligned}
\mathrm{AMO}(\mathrm{NAO})= & 0.28 \times \mathrm{NAO} \_ \text {Long }(\text { with } 6-\text { year lag }) \\
& -0.22 \times \mathrm{NAO} \_ \text {Short },
\end{aligned}
$$

where NAO_Long is the NAO index after low-pass filtering for periods longer than 60 months and NAO_Short is the NAO index after low-pass filtering for periods longer than 18 months. Figure 8 shows that AMO(NAO) and the observed AMO are significantly correlated with a coefficient of $\sim 0.5$, i.e. the $\mathrm{AMO}(\mathrm{NAO})$ accounts for $\sim 25 \%$ of the AMO variability, representing AMOC induced variability driven by the NAO.

\section{Summary and discussion}

We have analysed results from $1^{\circ}$ and $1 / 4^{\circ}$ NEMO ocean models and have found that model AMOC transport substantially depends on the strength of wind over the North Atlantic, although through different mechanisms at different timescales. At short timescales of about 1 year a weaker zonal wind over the North Atlantic (characterized by the January-June difference of mean sea level pressure between high and mid-latitudes in the North Atlantic) leads to an increase in the AMOC. We speculate this to be due both to changes in Ekman pumping at the western or eastern boundaries of the subtropical gyre immediately impacting cross-basin density gradients and hence the AMOC (subtropical forced variability), and to southward shifts in the Gulf Stream separation at the western boundary, leading to boundary waves and a rapid intensification of the AMOC. 
At this timescale, according to the values of correlation coefficients between January-June mean sea level pressure and AMOC transports from all model runs, about $35-50 \%$ of the AMOC variability can be explained by changes of JanuaryJune pressure difference between high and mid-latitudes over the North Atlantic.

At longer interannual timescales strong winds over the subpolar gyre (with NAO index as a measure of the wind strength) lead to an increase in the AMOC by means of an increase in deep water formation in the North Atlantic subpolar gyre (subpolar-forced variability). The change in top $1000 \mathrm{~m}$ density leads the AMOC change by about 4 years, while the fluctuations of deep layer density are correlated with the AMOC transport with zero lag, but this subpolar forcing mechanism only works in the higher-resolution model. In the longer 45 -year high-resolution model run then about $30 \%$ of the AMOC variability can be linked to density changes in the top $1000 \mathrm{~m}$ in the Labrador and Irminger seas 4 years earlier. The shorter high-resolution run gives weaker AMOC variability but with peaks and troughs at similar times, so that other differences are due to sensitivity to the initial conditions in the two runs.

An ocean-only model such as this can only generate AMOC variability of course from imposed surface driving or from internal ocean model variability, e.g. Hirschi et al. (2013). A coupled ocean-atmosphere model may lead to variability in the AMOC on longer timescales through variations in coupled modes, however we would still expect the last few years of any variation in these models to follow similar mechanisms to those discussed here, i.e. from air-sea forcing in either the subpolar or subtropical gyre, with impact on the AMOC from similar wave-generated processes.

The mechanisms of AMOC variability considered in this paper are in agreement with the results obtained by other authors: strong winds over the North Atlantic lead to an increase in turbulent fluxes (Marshall et al., 2001; Visbeck et al., 2003) that increase deep water formation in the North Atlantic subpolar gyre resulting in higher values of the AMOC. On the other hand a reduction in buoyancy-forced deep convection (Häkkinen and Rhines, 2004; Bersch et al., 2007) due to weaker winds or an increase in the northward heat transport by the ocean can lead to a decline in the AMOC (Fig. 4). It was also shown that horizontal resolution substantially influences the simulation of the AMOC driving processes, both in the water formation regions and further south down the western boundary. The intensification and deepening of convection in the Labrador Sea over several years only develops fully in the higher-resolution model and the western boundary waves which connect this region to the $26.5^{\circ} \mathrm{N}$ AMOC are reproduced better at higher resolution. As a result, higher-resolution models are able to reproduce the strong impact of deep water formation in the Labrador and Irminger seas on the AMOC transport. However, further studies are needed to explore the wind-forcing processes occurring near the boundaries in more detail.
Acknowledgements. Comments from two anonymous reviewers helped to significantly improve the paper. We also thank the editor for his effort which greatly improved the manuscript. This work was supported by the NERC through the NCEO and the RAPID-Watch Valor projects.

Edited by: A. J. G. Nurser

\section{References}

Adcroft, A., Hill, C., and Marshall, J.: Representation of topography by shaved cells in a height coordinate ocean model, Mon. Weather Rev., 125, 2293-2315, 1997.

Barnier, B. and the DRAKKAR Group: Eddy-permitting ocean circulation hindcasts of past decades, Clivar Exchanges, 12, 8-10, 2007.

Barnier, B., Madec, G., Penduff, T., Molines, J. M., Treguier, A. M., Le Sommer, J., Beckmann, A., Biastoch, A., Böning, C., Dengg, J., Derval, J., Durand, E., Gulev, S., Remy, E., Talandier, C., Theetten, S., Maltrud, M., McClean, J., and De Cuevas, B.: Impact of partial steps and momentum advection schemes in a global ocean circulation model at eddy-permitting resolution, Ocean Dynam., 56, 6543-6567, doi:10.1007/s10236-006-00821, 2006.

Bersch, M., Yashayaev, I., and Koltermann, K.: Recent changes of the thermohaline circulation in the subpolar north atlantic, Ocean Dynam., 57, 223-235, 2007.

Biastoch, A., Böning, C. W., Getzlaff, J., Molines, J. M., and Madec, G.: Causes of interannual-decadal variability in the meridional overturning circulation of the midlatitude north atlantic ocean, J. Climate, 21, 6599-6615, 2008.

Blanke, B. and Delecluse, P.: Variability of the Tropical Atlantic Ocean Simulated by a General Circulation Model with Two Different Mixed-Layer Physics, J. Phys. Oceanogr., 23, 1363-1388, 1993.

Böning, C., Scheinert, M., Dengg, J., Biastoch, A., and Funk, A.: Decadal variability of subpolar gyre transport and its reverberation in the North Atlantic overturning, Geophys. Res. Lett, 33, L21S01, doi:10.1029/2006GL026906, 2006.

Boyer, T. P., Garcia, H. E., Johnson, D. R., Locarnini, R. A., Mishonov, A. V., Pitcher, M. T., Baranova, O. K., and Smolyar, I. V.: World Ocean Database 2005, NOAA Atlas NESDIS 60, edited by: Levitus, S., 190 pp., U.S. Gov. Print. Off.: Washington D.C., 2006.

Bretherton, C. S., Widmann, M., Dymnikov, V. P., Wallace, J. M., and Blad, I.: The effective number of spatial degrees of freedom of a time-varying field, J. Climate, 12, 1990-2009, 1999.

Brodeau, L., Barnier, B., Treguier, A. M., Penduff, T., and Gulev, S.: An ERA40-based atmospheric forcing for global ocean circulation models, Ocean Modelling, 31, 88-104, doi:10.1016/j.ocemod.2009.10.005, 2009.

Chanut, J., Barnier, B., Large, W., Debreu, L., Penduff, T., Molines, J. M., and Mathiot, P.: Mesoscale eddies in the Labrador Sea and their contribution to convection and restratification, J. Phys. Oceanogr., 38, 1617-1643, 2008.

Cunningham, S. A., Kanzow, T., Rayner, D., Baringer, M. O., Johns, W. E., Marotzke, J., Longworth, H. R., Grant, E. M., Hirschi, J. J.-M., Beal, L. M., Meinen, C. S., and Bryden, H. L.: Temporal 
Variability of the Atlantic Meridional Overturning Circulation at 26.5 N, Science, 317, 935-938, 2007.

Dai, A. and Trenberth, K. E.: Estimates of freshwater discharge from continents: Latitudinal and seasonal variations, J. Hydrometeorol., 3, 660-687, 2002.

Dee, D. P. and Uppala, S.: Variational bias correction of satellite radiance data in the ERA-Interim reanalysis, Q. J. Roy. Meteorol. Soc., 135, 1830-1841, 2009.

Delworth, T. and Greatbatch, R.: Multidecadal thermohaline circulation variability driven by atmospheric surface flux forcing, J. Climate, 13, 1481-1495, 2000.

Deshayes, J. and Frankignoul, C.: Simulated variability of the circulation in the North Atlantic from 1953 to 2003, J. Climate, 21, 4919-4933, doi:10.1175/2008JCLI1882.1, 2008.

Dong, B. and Sutton, R. T.: Mechanism of Interdecadal Thermohaline Circulation Variability in a Coupled Ocean-Atmosphere GCM, J. Climate, 18, 1117-1135, doi:10.1175/JCLI3328.1, 2005.

Döscher, R., Böning, C., and Herrmann, P.: Response of circulation and heat transport in the north Atlantic to changes in thermohaline forcing in northern latitudes: A model study, J. Phys. Oceanogr., 24, 2306-2320, doi:10.1175/15200485(1994)024<2306:ROCAHT>2.0.CO;2, 1994.

Eden, C. and Willebrand, J.: Mechanism of Interannual to Decadal Variability of the North Atlantic Circulation, J. Climate, 14, 2266-2280, doi:10.1175/15200442(2001)014<2266:MOITDV>2.0.CO;2, 2001.

Fichefet, T. and Maqueda, M.: Sensitivity of a global sea ice model to the treatment of ice thermodynamics and dynamics, J. Geophys. Res., 102, 12609-12646, 1997.

Gary, S. F., Lozier, M. S., Boning, C. W., and Biastoch, A.: Deciphering the pathways for the deep limb of the Meridional Overturning Circulation, Deep-Sea Res. Pt. II, 58, 1781-1797, doi:10.1016/j.dsr2.2010.10.059, 2011.

Gent, P. R. and McWilliams, J. C.: Isopycnal Mixing in Ocean Circulation Models, J. Phys. Oceanogr., 20, 150-155, 1990.

Getzlaff, J., Böning, C., Eden, C., and Biastoch, A.: Signal propagation related to the North Atlantic overturning, Geophys. Res. Lett., 32, L09602, doi:10.1029/2004GL021002, 2005.

Goose, H. and Fichefet, T.: Importance of ice-ocean interactions for the global ocean circulation: A model study, J. Geophys. Res., 104, 23337-23355, 1999.

Haines, K., Valdivieso, M., Zuo, H., and Stepanov, V. N.: Transports and budgets in a $1 / 4^{\circ}$ global ocean reanalysis 1989-2010, Ocean Sci., 8, 333-344, doi:10.5194/os-8-333-2012, 2012.

Häkkinen, S. and Rhines, P.: Decline of Subpolar North Atlantic Circulation During the 1990s, Science, 304, 555-559, doi:10.1126/science.1094917, 2004.

Hermanson, L., Dunstone, N., Haines, K., Robson, K., Smith, J. D., and Sutton, R.: A novel transport assimilation method for the Atlantic Meridional Overturning Circulation at 26N, Q. J. Roy. Meteorol. Soc., online first, doi:10.1002/qj.2321, 2014

Hirschi, J. J.-M., Blaker, A. T., Sinha, B., Coward, A., de Cuevas, B., Alderson, S., and Madec, G.: Chaotic variability of the meridional overturning circulation on subannual to interannual timescales, Ocean Sci., 9, 805-823, doi:10.5194/os-9-805-2013, 2013.

Hodson, D. L. R. and Sutton, R. T.: The impact of resolution on the adjustment and decadal variability of the Atlantic Meridional
Overturning Circulation in a coupled climate model, Clim. Dynam., 39, 3057-3073, doi:10.1007/s00382-012-1309-0, 2012.

Huck, T., de Verdiere, A. C., Estrade, P., and Schopp, R.: Lowfrequency variations of the large-scale ocean circulation and heat transport in the North Atlantic from 1955-1998 in situ temperature and salinity data, Geophys. Res. Lett., 35, L23613, doi:10.1029/2008GL035635, 2008.

Kanzow, T., Cunningham, S. A., Johns, W. E., Hirschi, J. J.-M., Marotzke, J., Baringer, M. O., Meinen, C. S., Chidichimo, M. P., Atkinson, C., Beal, L. M., Bryden, H. L., and Collins, J.: Seasonal variability of the Atlantic meridional overturning circulation at $26.5^{\circ} \mathrm{N}$, J. Climate, 23, 5678-5698, 2010.

Large, W. G. and Yeager, S. G.: Diurnal to decadal global forcing for ocean and sea-ice models: The data sets and flux climatologies, Technical Report TN-460 + STR, NCAR, 105 pp., 2004.

Lazier, J., Hendry, R., Clarke, A., Yashayaev, I., and Rhines, P.: Convection and restratification in the Labrador Sea, 1990-2000, Deep-Sea Res. Pt. I, 49, 1819-1835, 2002.

Lohmann, K., Drange, H., and Bentsen, M.: Response of the North Atlantic subpolar gyre to persistent North Atlantic oscillation like forcing, Clim. Dynam., 32, 273-285, doi:10.1007/s00382008-0467-6, 2009a.

Lohmann, K., Drange, H., and Bentsen, M.: A possible mechanism for the strong weakening of the north Atlantic subpolar gyre in the mid-1990s, Geophys. Res. Lett, 36, L15602, doi:10.1029/2009GL039166, 2009b.

Lorbacher, K., Dengg, J., Böning, C. W., and Biastoch, A.: Regional Patterns of Sea Level Change Related to Interannual Variability and Multi-decadal Trends in the Atlantic Meridional Overturning Circulation, J. Climate, 23, 4243-4254, 2010.

Madec, G.: NEMO reference manual, ocean dynamics component: NEMO-OPA. Preliminary version. Note du Pole de modélisation, Institut Pierre-Simon Laplace (IPSL), France, No. 27, ISSN No. 1288-1619, 2008.

Madec, G., Delecluse, P., Imbard, M., and Levy, C.: OPA 8.1 general circulation model reference manual. Notes de l'IPSL, University P. et M. Curie, B102 T15-E5, Paris, No. 11, p. 91, 1998.

Marshall, J., Johnson, H., and Goodman, J.: A Study of the Interaction of the North Atlantic Oscillation with Ocean Circulation, J. Climate, 14, 1399-1421, doi:10.1175/15200442(2001)014<1399:ASOTIO>2.0.CO;2, 2001.

Penduff, T., Le Sommer, J., Barnier, B., Treguier, A.-M., Molines, J.-M., and Madec, G.: Influence of numerical schemes on current-topography interactions in $1 / 4^{\circ}$ global ocean simulations, Ocean Sci., 3, 509-524, doi:10.5194/os-3-509-2007, 2007.

Penduff, T., Juza, M., Brodeau, L., Smith, G. C., Barnier, B., Molines, J.-M., Treguier, A.-M., and Madec, G.: Impact of global ocean model resolution on sea-level variability with emphasis on interannual time scales, Ocean Sci., 6, 269-284, doi:10.5194/os6-269-2010, 2010.

Robson, J., Sutton, R., Lohmann, K., Smith, D., and Palmer, M. D.: Causes of the Rapid Warming of the North Atlantic Ocean in the Mid-1990s, J. Climate, 25, 4116-4134, doi:10.1175/JCLI-D-1100443.1, 2012.

Roussenov, V., Williams, R., Hughes, C., and Bingham, R.: Boundary wave communication of bottom pressure and overturning changes for the north atlantic, J. Geophys. Res, 113, C08042, doi:10.1029/2007JC004501, 2008. 
Roullet, G. and Madec, G.: Salt conservation, free surface, and varying levels: a new formulation for ocean general circulation models, J. Geophys. Res., 105, 23927-23942, 2000.

Simonnet, E., Ghil, M., and Dijkstra, H.: Homoclinic bifurcation in a quasi-geostrophic double-gyre circulation, J. Marine Res., 63, 931-95, 2005.

Simmons, A., Uppala, S., Dee, D., and Kobayashi, S.: ERA-Interim: New ECMWF reanalysis products from 1989 onwards, ECMWF Newsletter, 110, 25-35, 2007.

Smith, G. C. and Haines, K.: Evaluation of the $S(T)$ assimilation method with the Argo dataset, Q. J. Roy. Meteorol. Soc., 135, 739-756, 2009.

Smith, G. C., Haines, K., Kanzow, T., and Cunningham, S.: Impact of hydrographic data assimilation on the modelled Atlantic meridional overturning circulation, Ocean Sci., 6, 761774, doi:10.5194/os-6-761-2010, 2010.

Stepanov, V. N., Haines, K., and Smith, G. C.: Assimilation of RAPID observations into an ocean model, Q. J. Roy. Meteorol. Soc., 138, 2105-2117, doi:10.1002/qj.1945, 2012.
Taylor, H. and Stephens, J. A.: The North Atlantic Oscillation and the latitude of the Gulf Stream, Tellus A, 50, 134-142, 1998.

Visbeck, M., Chassignet, E., Curry, R., Delworth, T., Dickson, B., and Krahmann, G.: The ocean's response to North Atlantic Oscillation variability, in: The North Atlantic Oscillation: Cinematic Significance and Environmental Impact, 113-146, Am. Geophys. Un., 2003.

Volkov, D. L., Lee, T., and Fu, L. L.: Eddy-induced meridional heat transport in the ocean, Geophys. Res. Lett., 35, L20601, doi:10.1029/2008GL035490, 2008.

Wang, D. P. and Mooers, C. N. K.: Coastal-trapped waves in a continuously stratified ocean, J. Phys. Oceanogr., 6 , 853-863, 1976.

Yashayaev, I., Bersch, M., and Van Aken, H. M.: Spreading of the Labrador Sea Water to the Irminger and Iceland basins, Geophys. Res. Lett., 34, 10602, doi:10.1029/2006GL028999, 2007.

Zhang, R.: Latitudinal dependence of Atlantic meridional overturning circulation (AMOC) variations, Geophys. Res. Lett., 37, L16703, doi:10.1029/2010GL044474, 2010. 